\title{
LA FUNCIÓN DEL COMPLIANCE \\ EN EL ANÁLISIS DE LA RESPONSABILIDAD PENAL DE LA PERSONA JURÍDICA
}

STALIN RAZA CASTAÑEDA ${ }^{1}$

\section{RESUMEN}

En el presente ensayo se analizarán 6 aspectos fundamentales: 1. El estado de la cuestión en materia de responsabilidad penal de las personas jurídicas, desde un abordaje tanto teórico como práctico;

2. La compatibilidad constitucional de la responsabilidad penal de las personas jurídicas;

3. Los modelos de imputación de las personas jurídicas conocidos hasta la actualidad;

4. Los problemas de la responsabilidad penal de las personas jurídicas con la Dogmática Penal estándar;

5. Las funciones del compliance para evaluar la responsabilidad penal de las personas jurídicas; y,

6. La necesidad o no de elaborar una nueva Dogmática Penal para los casos de responsabilidad penal de las personas jurídicas y las funciones del compliance en tal dogmática.

PALABRAS CLAVE: Responsabilidad penal de las personas jurídicas, compliance, Teoría de Sistemas, modelo de transferencia, culpa por defecto de organización, autorregulación, heterorregulación, compliance officer, riesgos especiales, buen ciudadano corporativo, culpabilidad constructivista.

1 Docente Universitario Universidad Central del Ecuador, Universidad Andina Simón Bolívar e Instituto de Altos Estudios Nacionales 


\section{ABSTRACT}

The following essay will contain 6 fundamental aspects:

1. A theoretical and practical approach to the state of art for attributing criminal responsibility to legal entities.

2. How attributing criminal resposibility to legal entities is compatible with law governed constitutional democracies.

3. The known models of attributing criminal responsibility to legal entities.

4. An analysis of the conflict between attributing criminal responsibility to legal entities and the existing structure of criminal law and criminal procedures.

5. Compliance's role in determining criminal responsibility to legal entities.

6. An evaluation of whether or not it is necessary to improve the structure of criminal law and criminal procedures so that they can be applied in affairs of criminal responsibility to legal entities; and if it is the case, how compliance will support the new structure.

\section{KEY WORDS:}

Liability criminal of the legal persons, compliance, Theory of Systems, model of transfer, guilt by defect of organization, selfregulation, hetero-regulation, compliance officer, special risks, good corporate citizen, constructivist guilt. 


\section{INTRODUCCIÓN}

El título del presente trabajo presupone que tanto las nociones del compliance en sentido general, como del específico compliance penal -si acaso puede hablarse de él- son conocidas por haber sido objeto de un tratamiento doctrinario medianamente exhaustivo; sin embargo de lo cual, se considera indispensable dedicar una primera parte a una breve reseña de lo que se conoce como "estado de la cuestión", en la que especialmente se dará cuenta de los argumentos a favor y en contra de la responsabilidad penal de las personas jurídicas y su compatibilidad con los principios fundamentales de un Derecho Penal acorde con la noción del Estado Constitucional (acto, lesividad, culpabilidad y ultima ratio), para concluir identificando los dos principales modelos de imputación actualmente aceptados tanto por la doctrina como por la jurisprudencia comparada, con el propósito de determinar cuál de ellos satisface de mejor forma tales principios.

Una vez hecha tal determinación, la segunda parte del trabajo, que constituye su objeto central, partirá de otro supuesto general, que es la necesidad de contar con un compliance como instrumento para analizar el comportamiento conforme a Derecho de la persona jurídica y de esta manera establecer si su organización interna ha sido o no defectuosa, instrumento que ayudará a determinar su grado de participación en la comisión de delitos desde su estructura empresarial. En tal sentido, esta parte del trabajo buscará ensayar algunas respuestas a las siguientes preguntas: 1.¿Qué función tiene el compliance en el modelo de responsabilidad penal escogido?; 2. ¿Cuáles son los problemas que enfrenta el compliance en relación con las categorías de la dogmática penal estándar?; y, 3. ¿Cuál es la función del compliance al momento de evaluar la responsabilidad penal de la persona jurídica? 


\section{RESPONSABILIDAD PENAL DE LAS PERSONAS JURÍDICAS Y COMPLIANCE:}

Como ya se anticipó, resulta indispensable tener en cuenta que la causa necesaria y suficiente para la existencia del denominado compliance aplicado al ámbito penal, es la aceptación teórica y la constatación práctica de la responsabilidad penal de las personas jurídicas; aspecto doctrinariamente polémico y por ello, ampliamente debatido, sobre el cual la teoría estándar da cuenta, recurriendo a dos grupos de argumentos, unos a favor; y, otros en contra de esta forma de imputación penal. ${ }^{2}$

En el primer grupo destacan argumentos de carácter utilitarista relacionados con la complejidad y globalidad de las actividades de la empresa, así como con la necesidad de proveer respuestas jurídicas idóneas a un fenómeno que parece haber superado las capacidades explicativas de las categorías dogmáticas hasta ahora existentes ${ }^{3}$; y en el segundo, objeciones relacionadas con el sentido del "injusto" penal, del que desde KANT han sido sujetos de imputación exclusivos las personas físicas, bajo la premisa de autonomía de la voluntad y consecuentemente, de individualización del reproche ${ }^{4}$; así como objeciones de corte igualmente utilitarista relacionadas con la finalidad preventiva del Derecho Penal, de acuerdo con las cuales, las penas impuestas a las personas jurídicas no pertenecen al ámbito estrictamente penal, sino cuando más, al derecho administrativo sancionatorio;

2 Sobre una completa referencia de estos argumentos, véase Bacigalupo, Enrique, Compliance y Derecho Penal, Hammurabi, Buenos Aires, 2012, pp. 99-120

3 Ibid, p. 101.

4 Ibid. p. 103. 
y en tal sentido, hablar de una supuesta responsabilidad penal de la persona jurídica no acredita la finalidad preventiva de la pena strictu sensu, sino que por el contrario, configura una suerte de responsabilidad objetiva, mucho más cercana a la noción anglosajona de la strict laibility. ${ }^{5}$

En la línea de justificar la necesidad de responsabilizar penalmente a la persona jurídica, merecen destacarse los intentos de fundamentación que se han hecho a partir de la denominada "Teoría de sistemas" de Nicklas LUHMANN ${ }^{6}$ por autores que la han utilizado para caracterizar a la organización de la empresa como un sistema autopoiético capaz de generar relaciones comunicativas que configuran una verdadera autonomía funcional de los entes ficticios, dotándolos de capacidades cognitivas propias que los convierten en "máquinas históricas no triviales", a partir de lo cual deducen su competencia como sujetos de imputación en general y de imputación penal, en particular ${ }^{7}$.

Dada la capacidad explicativa de esta teoría, se abundará sobre ella y se la utilizará más adelante como referencia fundamental cuando se analice la posibilidad de construir ${ }^{8}$ una dogmática

5 En la cultura jurídica anglosajona la noción de strict laibility en materia de reparación de daños es mucho más integral y no tiene una diferenciación tan rígida en responsabilidad administrativa, civil y penal como la tiene la tradición jurídica europeocontinental.

6 LUHMANN, Niklas, Sistemas Sociales: Lineamientos para una teoría general, Anthropos, Barcelona, 1998.

7 Gómez-JARA Díez, “Autoorganización empresarial y auto rresponsabilidad empresarial", Revisa Electrónica de Ciencia Penal y Criminología, 2006. http:/ / criminet.ugr.es/recpc-

8 El uso del término "construir" en esta parte no es casual, dado que precisamente se considera a la Teoría de Sistemas Sociales de 
penal específica para la responsabilidad penal de la persona jurídica, así como para la existencia y funciones del compliance, sin dejar por supuesto de advertir las diferentes objeciones que se le puedan hacer.

En la misma línea pero como alternativa a estos grupos de argumentos, se considera también la posibilidad de fundar la responsabilidad penal de las personas jurídicas teniendo en cuenta los contenidos axiológicos de lo que se conoce como "Constitución económica", cuyos alcances estarán condicionados por el énfasis más liberal o más intervencionista que pongan los estados en la actividad económica; y es así que existen constituciones en América Latina, como la ecuatoriana que han optado por sistemas de economía centralizada, que tratan sin embargo de conciliarse con declaraciones holísticas referidas a nociones como la "pacha mama", el "buen vivir" o los "derechos de la naturaleza", para justificar una caracterización del sistema económico como "social y solidario", "funcional al ser humano", reconociéndolo como "sujeto y fin" y propendiendo a un equilibrio entre "sociedad, estado y mercado", importancia de un régimen de desarrollo "planificado", que entre otros ha de perseguir como objetivos, "...la distribución igualitaria de los beneficios del desarrollo, de los medios de producción y la generación de trabajo digno y estable..." ${ }^{10}$, para cuyo efecto impone al estado la obligación de “...Impulsar el

LUHMANN y a su aplicación al análisis de la responsabilidad penal de las personas jurídicas, como tributarias del Constructivismo Filosófico y Sociológico, aunque existen autores que consideran que Luhmann es "inclasificable"

9 Constitución de la República del Ecuador, Artículo 283.

10 Ibid. Artículo 276.2 
desarrollo de las actividades económicas mediante un orden jurídico e instituciones políticas que las promuevan, fomenten y defiendan..."11.

Estos principios, sumados a los mecanismos de democracia directa y participación ciudadana, así como al cambio de paradigma epistémico que podría constituir el reconocimiento de los derechos de la naturaleza y la responsabilidad intergeneracional, bien podría decirse que representan el núcleo duro de una Constitución económica que sin lugar a dudas asigna al estado un rol muy diferente de aquel que tendría en un diseño de "economía social de mercado" o cualquiera otro de corte más liberal, imponiéndole claras obligaciones de intervención y regulación orientadas a alcanzar ese deseable "equilibrio" entre sociedad y mercado; obligaciones que no derivan ya meramente de un programa político, sino de la fuerza vinculante de la propia Constitución.

Estos anclajes interpretativos que encuentran amplia repercusión práctica dado el carácter normativo directo de los contenidos axiológicos de la Constitución en un estado Constitucional de Derecho, sumados al nuevo paradigma de la titularidad de los derechos -y valga anticipar, también de las obligaciones-, de acuerdo con el cual, el ser humano deja de ser titular exclusivo de los mismos para compartir ese espacio con las comunidades, pueblos, nacionalidades, colectivos y aún, la propia naturaleza ${ }^{12}$, bien puede considerarse como una habilitación tanto teórica como metodológica que permita justificar la incorporación al ordenamiento jurídico de la

\footnotetext{
11 Ibid. Artículo 277.5

12 Ibid. Artículo 10
} 
responsabilidad penal de la persona jurídica, a partir de la constatación de que su atípica condición de ente ficticio no invalida la posibilidad de construir un igualmente atípico juicio de reproche apartado de consideraciones ontologistas sobre la "naturaleza" de los atributos y consecuencias resultantes de su denominación como "persona", para lo cual es necesario superar las limitaciones del lenguaje y las restricciones de los conceptos que en casos como estos, podrían obscurecer el alcance de los significados.

Esto no quiere decir en absoluto que la responsabilidad penal de las personas jurídicas se encuentre vedada en aquellos estados de corte más liberal o menos intervencionista, pues tal afirmación contradiría la evidencia empírica que se presentará más adelante respecto de casos paradigmáticos de grandes fraudes que se produjeron justamente en estados que bajo ningún concepto podrían considerase como intervencionistas. Lo único que se intenta con este argumento es mostrar que la justificación de tal forma de responsabilidad penal encuentra mayor facilidad en aquellos diseños institucionales donde además de criterios doctrinarios, existen normas jurídicas de la mayor jerarquía que pueden convertirse en el fundamento de dicha responsabilidad, afirmación que se la hace desde una perspectiva estrictamente descriptiva, quedando para el ámbito prescriptivo evaluar la legitimidad y conveniencia de normas constitucionales como las citadas, donde inevitablemente aparecerá el debate de hasta dónde resulta lícito injerir en la autonomía individual bajo el argumento de proteger intereses colectivos.

Por otra parte, es casi unánime el actual reconocimiento que se hace sobre la titularidad de las personas jurídicas de ciertos 
derechos, ya sean de carácter económico ${ }^{13}$ o de carácter instrumental como los de tutela judicial efectiva o debido proceso, estos últimos justificados por servir a fines que tienen que ver más bien con la vigencia del Estado del Derecho ${ }^{14}$ que a las características particulares de las personas jurídicas, lo que haciendo un ejercicio de razonamiento analógico en la modalidad del argumento a contrario, bien puede llevarnos a reflexionar que es posible también, por razones igualmente instrumentales construir juicios de imputación acerca de las mismas personas jurídicas, teniendo presente que son razones exclusivamente normativas las que fundamentan la necesidad de proteger bienes jurídicos, ante lo cual, se considera que no existen impedimentos de carácter lógico, teórico ni metodológico para que se pueda también construir normativamente un modelo de imputación propio de los entes ficticios ${ }^{15}$.

Para finalizar este análisis de los argumentos a favor y en contra de la responsabilidad penal de las personas jurídicas, resulta indispensable considerar las objeciones provenientes del denominado Garantismo Penal, en tanto corriente de pensamiento jurídico que se opone a toda expansión del ámbito de actuación del Derecho Penal y postula la necesidad de un

13 Sobre una propuesta de diferenciación entre derechos fundamentales y derechos patrimoniales veáse por todos, FERRAJOLI, Luigi, Los Fundamentos de los derechos fundamentales, Trotta, Madrid, 2005.

14 Sobre el particular, un interesante análisis de Raúl NúÑEZ MARÍN, respecto del estado de debate de este tema en el Sistema Interamericano de Derechos Humanos, así como en otros sistemas, como el europeo. disponible en http:/ / perspectivasinternacionales. javerianacali.edu.co/pdf/6.1-07.pdf

15 Precisamente la Teoría de la Imputación Objetiva enfatiza en las consideraciones de carácter normativo por sobre aquellas de carácter "causal" o "final" para sustentar todo su esquema teórico. 
Derecho Penal mínimo (y en algunas variantes con tendencia al abolicionismo), opuesto incluso a que reivindicaciones como las de género o las ecologistas utilicen la herramienta del Derecho Penal para procesar sus conflictos ${ }^{16}$, para lo cual se remiten casi siempre a la denominada "esfera de lo indecidible" constituida por los derechos en general; y el de libertad personal, en particular.

A visiones como estas, bien podrían oponerse objeciones que podrían provenir de quienes defiendan la noción de Democracia Deliberativa, pues ellos afirmarían que no existe tal "esfera de lo indecidible" sino que por el contrario todos los aspectos que interesan a una sociedad y dentro de ellos, especialmente los relacionados con el Derecho Penal, pueden y deben someterse a un debate amplio e inclusivo que contemple y trate de conciliar los intereses de todos los involucrados ${ }^{18}$, sin que esto contraríe la noción de ultima ratio del Derecho Penal, ni que aliente políticas de "mano dura" o "populismo penal", sino que por el contrario se convierta en una herramienta de racionalización del Derecho Penal pero teniendo en cuenta las particularidades históricas, económicas, políticas y culturales de cada sociedad para determinar cuáles han de ser los bienes jurídicos objeto de

16 Ávila Santamaría, Ramiro, La (in) justicia penal en la democracia constitucional de derechos: una mirada desde el garantismo penal, Universidad Andina Simón Bolívar, Quito, 2013, p. 29.

17 Ferrajoli, Luigi. "La esfera de lo indecidible y la división de poderes", Estudios Constitucionales, Año 6, No. 1, Centro de Estudios Constitucionales, Universidad de Talca, Chile, 2008, pp. 337-343, disponible en http://www.cecoch.cl/docs/pdf/revista_ano6_1/ Laesfera17.pdf.

18 Gargarella, Roberto, De la injusticia penal a la justicia social, Siglo del Hombre, Universidad de los Andes, Bogotá, 2008. 
protección en ese contexto y evitar así trasplantes normativos acríticos de otras realidades, que aplicados al caso concreto de la responsabilidad penal de las personas jurídicas, puedan o no determinar en su necesidad, teniendo presente que responder a dinámicas empresariales de emporios globalizados como los que ocasionaron los grandes fraudes que se verán a continuación requiere de herramientas jurídicas de una intensidad diferente a las que deben utilizarse en contextos donde la estructura societaria de las empresas sigue siendo cerrada y los sistemas de toma de decisiones, altamente concentrados.

Por otra parte, es necesario advertir que existen dos perspectivas desde las que se puede abordar tanto el tratamiento de la responsabilidad penal de las personas jurídicas, como del compliance: la primera relacionada con los aspectos teóricos que han ocupado la atención de la dogmática penal desde hace más de cien años, referidos como se dijo, a la posibilidad o no de aceptar la responsabilidad penal de las personas jurídicas; y en caso de ser así, el rol que desempeñaría el compliance dentro del particular modelo de imputación que habría de construirse; y la segunda, desde un carácter mucho más empírico y pragmático, referida a la constatación de casos emblemáticos ocurridos en las postrimerías del siglo pasado e inicios del presente, que mostraron la necesidad de incorporar esta forma de responsabilidad a los ordenamientos jurídicos, así como la insuficiencia de las herramientas tradicionales del Derecho Penal para explicar tanto los fenómenos delincuenciales que se produjeron utilizando los aparatos empresariales, como las formas más idóneas de respuesta que permitan imputar responsabilidad penal, determinar sanciones y reparar los millonarios perjuicios ocasionados por los fraudes cometidos por y a través de grandes empresas, que se erigieron como actores muy distintos a los 
sujetos activos de delitos conocidos hasta entonces por la teoría penal estándar.

Resulta entonces paradójico que a pesar de la controversia teórica aún mantenida, en el ámbito práctico esta discusión haya sido largamente superada y que actualmente la responsabilidad penal de las personas jurídicas se encuentre contemplada en la mayoría de legislaciones del mundo; así, en Europa en los códigos penales de Bélgica, Dinamarca, Eslovenia, Francia, Finlandia, Portugal, Suecia, Italia, Holanda; en EEUU, en las leyes Sarbanes Oxley Act y Foreing Corrupt Practice Act; y en Latinoamérica, en el Código Penal chileno ${ }^{19}$ o la Ley 1474 de Colombia; al tiempo que haya sido también desarrollada por los Tribunales Supremos de Alemania, España y Argentina ${ }^{20}$, que realizan importantes aportes desde la fuente jurídica del Derecho Jurisprudencial.

Precisamente por esto, se considera necesario abordar esta segunda perspectiva (práctica), para lo cual, se ofrece una síntesis de los hechos de seis casos que se asumen como relevantes para mostrar cómo la dinámica de la actividad empresarial y la complejización de los instrumentos financieros superaron con creces los debates doctrinarios acerca de la aceptación o no de la responsabilidad penal de la persona jurídica; y aún más allá, de la empresa en tanto actividad económica organizada, como sujeto capaz de ocasionar fraudes de gran magnitud, afectando bienes jurídicos a gran escala y con carácter transnacional.

19 BACIGALUPO, Silvina, La responsabilidad penal de las personas jurídicas, Bosch, Barcelona, 1998

20 En Alemania se pueden mencionar los casos "Kanter/Weyrauch" (2006) y "Siemens/KWU” (2008), en España, el caso del "síndrome tóxico o del aceite de colza" (1992); y en Argentina, el caso "Fly Machine" (2006) 


\section{CASOS PARADIGMÁTICOS}

El primero y más citado debido al escándalo que causó es el caso de ENRON $^{21}$, emporio norteamericano dedicado a las industrias de gas y electricidad que hizo crisis en el año 2001, ocasionando pérdidas económicas aproximadas de USD 690 millones y deudas por la estratosférica suma de USD 150 billones. Los problemas de Enron se presentaron principalmente debido al manejo especulativo de un producto denominado "derivados financieros", que fue trasplantado desde la actividad bursátil a la industria del gas y la electricidad, por un sofisticado y hasta entonces reputado como altamente exitoso equipo de técnicos, encargados de manejar lo que ellos denominaron el "Banco del Gas".

El procedimiento funcionaba mediante la intermediación especulativa entre vendedores y compradores de gas y electricidad, a través de la suscripción de contratos "a futuro" en los que Enron garantizaba a los partícipes de la industria un precio fijo durante un número determinado de años -generalmente diez o veinte-, asumiendo por su cuenta el riesgo por fluctuación, que consideraba minimizado por su presencia monopólica en el mercado. El problema empezó a acumularse cuando titularizó estos contratos a futuro (swaps) ${ }^{22}$ y los registró como activos

21 Los hechos de este caso han sido consultados en http://www. academia.edu/3480864/El_caso_Enron_Fracaso_de_una_de_las_ empresas_mas_poderosas_de_estados_unidos.

La noción de los "derivados financieros" (swaps) es ampliamente conocida en el Derecho Bancario como uno de los contratos más complejos de tal actividad. Sobre el particular, FERRI-RICCHI, Amedeo, El Contrato de Swap como tipo de derivado, tesis doctoral, Universidad Complutense de Madrid, Facultad de Derecho, Departamento de Derecho Mercantil, Madrid, 2013, disponible en http:/ / eprints.ucm.es/22814/1/T34726.pdf. 
de la empresa, utilizando el sistema de valoración denominado mark-to-market para lo cual empleó su gran influencia política y consiguió presionar al órgano regulador, la Securities and Exchange Commission, que autorizó el uso de este sistema en una industria distinta al mercado bursátil. Antes de la adopción de este sistema, la empresa podía registrar como activos en su balance, únicamente el dinero efectivamente ingresado como resultado de los cobros de los contratos a futuro; sin embargo, con el nuevo sistema, se podían registrar en una sola operación inicial, la totalidad de valores que se estimaba recibir durante los plazos de vigencia de tales contratos, estableciendo discrecionalmente los valores por fluctuaciones de mercado, lo que determinaba a su vez, que los activos reflejen valores sobredimensionados y ficticios, pues los cálculos se hacían en base a estimaciones inciertas sobre los precios futuros del gas y la electricidad.

Una vez articulado este mecanismo, el siguiente paso era la creación de las denominadas "sociedades de propósito específico", cuyos activos estaban conformados en su totalidad por paquetes de contratos a futuro titularizados y valorados según el sistema contable antes descrito, para de esta manera presentar balances inflados, en base a los cuales dichas sociedades obtenían créditos de dinero fresco que permitía mantener los flujos de liquidez necesaria para mantener las operaciones; al tiempo que permitían sobrevalorar la cotización de las acciones en bolsa, tanto de Enron como de sus sociedades de propósito específico a nivel mundial, generando un efecto de altísima demanda para la compra de esas acciones, lo que a su vez les permitió ofertar otro producto financiero consistente en las denominadas "opciones de compra de acciones", por medio del cual, grupos de inversionistas, generalmente fondos de pensiones de jubilados pactaban con las empresas adquirir paquetes accionarios a futuro en un valor estimado del precio de 
la acción para cuando llegue la fecha de realización de la opción, mecanismo que les permitía igualmente apalancarse con recursos frescos provenientes de estas inversiones.

Uno de los signos inequívocos de la crisis de Enron fue en un primer momento la ejecución de las opciones de compra y a su vez, la venta de acciones de las que eran titulares los principales directivos de la empresa, pero al mismo tiempo, el impedimento de que puedan hacer lo mismo los empleados de inferior rango, lo que despertó las alarmas en un primer momento, del propio comité interno de auditoría, luego de la misma Securities and Exchange Commission y finalmente, del Departamento de Justicia de los EEUU que inició una investigación formal y presentó cargos criminales contra los principales personeros de Enron, así como de la firma auditoria Artur Andersen, a quien le imputaron responsabilidad como cómplice, entre otras cosas, por la omisión en sus deberes de vigilancia y control al momento de dictaminar sobre los balances, pero además, por la destrucción de registros contables de gran parte de las operaciones, una vez que se conoció del proceso de investigación llevado a efecto.

El caso adquirió características de escándalo mediático debido al descubrimiento de las relaciones de Enron con el financiamiento de campañas políticas de importantes personajes, entre los que figuraba el propio George W. Bush, así como su Vicepresidente, Dick Cheney y por el sospechoso suicidio del Vicepresidente Ejecutivo de la empresa. Luego de una ardua batalla judicial, el caso concluyó con una sentencia a sus principales personeros, así como a los personeros de la firma auditora, a veinte y cuatro años de privación de libertad, reducida a catorce en el caso del principal administrador sobreviviente, pues varios de ellos murieron durante el juicio. 
Otro de los casos paradigmáticos de fraudes económicos a gran escala fue el de la empresa norteamericana de telecomunicaciones WORLDOCOM ${ }^{23}$ ocurrido en el año 2002, que presentódistorsiones contables por USD 11,000 millones y ocasionó pérdidas a sus accionistas por un monto de USD 180,000 millones. El mecanismo utilizado en esta ocasión fue el maquillaje contable de las cuentas de ingresos a través del registro de valores que correspondían a gastos, como si en realidad se tratara de inversiones, para de esta forma obtener de manera fraudulenta créditos bancarios en base a una situación patrimonial falsa y al mismo tiempo, utilizando esa posición financiera adulterada, cotizar sus acciones en bolsa con precios sobrevalorados.

De manera similar al caso Enron, los principales adquirentes de los paquetes accionarios fueron fondos de pensiones de trabajadores y jubilados, que sufrieron un perjuicio estimado de USD 1.000 millones; así como el despido de 20.000 trabajadores de la empresa nivel global. Se formularon cargos criminales por fraude y conspiración contra sus principales administradores, directores y la firma auditora externa que coincidencialmente fue también Artur Andersen y se establecieron sentencias que oscilaron entre los diez y veinte y cinco años.

En Europa son célebres los casos PARMALAT ${ }^{24}$ y SIEMENS ${ }^{25}$ ocurridos en Italia y Alemania, respectivamente. El primero de

23 http:// fraudescontables.blogspot.com,y http:/ / escritosderechopenalcamiloencisov.blogspot. com/2013/05/grandes-fraudes-financieros-lecciones.html.

24 http://interamerican-usa.com/articulos/Gob-Corp-Adm/ Art- Parmalat.htm

25 http://www.academia.edu/3667747/Caso_Siemens 
ellos en el año 2003 con un agujero contable reportado de 4.000 millones euros, así como la falsedad en los balances cometida durante quince años que reportó un monto de 14.000 millones de euros en activos inexistentes. El caso se descubrió cuando se pretendió entregar como contragarantía de un crédito por 496,5 millones euros, un certificado de inversión en el Bank of América por 3.950 millones euros, que tenía como titular a una firma subsidiaria llamada Bonlat, domiciliada en la Islas Cayman y que resultó ser falsificado. Las investigaciones establecieron que se distrajeron dineros de Parmalat a empresas de familiares principal ejecutivo, Calisto Tanzi, quien recibió una sentencia de dieciocho años dictada por un tribunal de Parma, que lo declaró culpable de quiebra fraudulenta y asociación ilícita, junto con otros trece ex ejecutivos.

El caso Siemens ${ }^{26}$ se conoció en el año 2007 y ocasionó un perjuicio patrimonial estimado de 2.000 millones de euros que fueron desviados a lo que se denominó como "cajas negras", consistentes en cuentas radicadas en paraísos fiscales, cuyos fondos servían para pagar sobornos a funcionarios gubernamentales de diferentes países, con el objeto de conseguir contratos para la firma. El Tribunal Federal Alemán condenó penalmente a los administradores por el delito de administración desleal ocasionada por violación de sus deberes de cuidado ${ }^{27}$ y

26 El caso central, puesto que existen otros procesos en los diferentes países donde se acusa a la empresa de haber entregado sobornos a cambio de contratos con los Estados. Precisamente uno de esos casos se radicó en Argentina, donde Siemens fue beneficiario de un millonario contrato para la elaboración de los DNI.

27 En este caso, el Tribunal Federal Alemán por primera vez se pronunció en el sentido de que existe perjuicio patrimonial aunque los recursos desviados se hayan utilizado para beneficio de la propia 
en los EEUU se condenó además a la empresa a pagar multas por aproximadamente USD 600 millones.

Finalmente conviene referirse a los casos JP MORGAN ${ }^{28}$ y BANK OF AMERICA $^{29}$, el primero tiene que ver con operaciones de alto riesgo realizadas por un operador del banco, llamado Bruno Iskil, conocido también con el seudónimo de "la ballena de Londres", precisamente por la temeridad de sus operaciones y por haber llegado a tener una posición en bonos de hasta USD 100 millones precisamente para esta operación, que consistía en la venta de Credit Swaps Dafauts (CDS), derivados financieros que conformaban paquetes de bonos emitidos por empresas de alto rendimiento y bajo riesgo, que por lo mismo debían mantener razonablemente su precio en el mercado de valores; transacción por la que el vendedor cobraba a los compradores una prima a cambio de asumir el riesgo de cubrir el diferencial de cambio en caso de que los precios bajen, que fue lo que precisamente ocurrió, debido entre otras causas, a los coletazos de la crisis de la deuda europea y a lo inusual del monto de la operación, que generó nerviosismo en los mercados y produjo una pérdida estimada de USD 2 billones, así como el inicio de procesos penales contra sus principales directivos bajo los cargos de fraude de valores, fraude electrónico, conspiración, realizar falsas presentaciones

empresa a través de la obtención de contratos que le reportaban utilidades, bajo el criterio de que el uso de esos recursos en propósitos diferentes a los que fueron oficialmente asignados, constituye en sí una forma de perjuicio patrimonial. Sobre el particular, BACIGALUPO, Enrique, Op. Cit. pp. 165-171.

http:/ / queaprendemoshoy.com/el-caso-jp-morgan-que-fue-loque-sucedio-realmente ii/?preview=true\#.T7wjX0Vp5nA. 
a la Comisión Nacional de Valores de Estados Unidos (SEC) y falsificar libros y registros, lo que forzó a que deba llegar a acuerdos tanto con la Fiscalía como con la SEC, la Reserva Federal y la Oficina de Control de la Moneda, así como con el supervisor financiero de Reino Unido para pagar multas por montos que oscilaron entre USD 700 y 800 millones $^{30}$.

En cuanto al Bank of America, en la actualidad se encontraría negociando con el Departamento de Justicia de los Estados Unidos, acuerdos reparatorios por montos que oscilan entre USD 16.000 y 17.000 millones, para evitar los cargos de fraude proveniente del engaño a sus clientes por omitir información sobre el respaldo de bonos garantizados con créditos hipotecarios altamente riesgosos por la falta de pago resultante de la crisis de 2008, conocida como "burbuja inmobiliaria" en los Estados Unidos.

Como se puede ver, en todos estos casos entró a debate la suficiencia o no de las modalidades de responsabilidad conocidas y por supuesto, el alcance de la responsabilidad penal, que aprovechando las peculiaridades del sistema anglosajón permitió tanto la imputación de delitos a las personas físicas, como la de cargos criminales a las propias empresas, imponiéndoles multas cuantiosas u obligándoles a celebrar acuerdos con los perjudicados. No ocurrió lo mismo en los casos de Parmalat y Siemens, pues tanto en Alemania como en Italia, países de cultura jurídica europeo-continental como era previsible, se generó un intenso debate dogmático sobre la responsabilidad penal de las personas jurídicas, que desembocó en el primer caso,

30 http://www.elmundo.es/elmundo/2013/09/17/economia/ 1379407595.html. 
en la elaboración de varias sentencias que trataron de fundar esta modalidad de responsabilidad; y en el segundo, en la regulación exhaustiva de la misma por vía legislativa.

COMPATIBILIDAD CONSTITUCIONAL DE LA RESPONSABILIDAD PENAL DE LAS PERSONAS JURÍdICA Y MODELOS DE IMPUTACIÓN:

Es conocido que para hablar de un Derecho Penal compatible con un modelo de estado constitucional deben satisfacerse al menos cuatro principios fundamentales: acto, lesividad, culpabilidad y ultima ratio. Puesto que se han analizado ya los argumentos teóricos a favor y en contra de la responsabilidad penal de la persona jurídica, así como que se ha dado cuenta de que en los hechos, dicha responsabilidad existe en la mayoría de legislaciones del mundo y es progresivamente reconocida también mediante fuente jurisprudencial, corresponde ahora contrastar si tal modalidad de responsabilidad penal resulta $\mathrm{o}$ no compatible con dichos principios.

Como se sabe, según el principio de acto, en un estado democrático y constitucional solo se puede atribuir responsabilidad penal a alguien por sus "actos" cometidos y no por sus condiciones personales, en esto precisamente se diferencia el Derecho Penal "de acto" del denominado Derecho Penal "de autor". Ahora bien, en cuanto a la responsabilidad penal de las personas jurídicas, la primera interrogante que surge es si ellas pueden o no cometer "actos" en el sentido penalmente relevante y este es uno de los aspectos que más controversia ha causado, pues de acuerdo con las teorías vicarias del Derecho Penal, el acto constituye una manifestación de la conducta y de la voluntad estrictamente humanas ${ }^{31}$, convirtiéndose

31 En este punto utilizo el término "teorías vicarias" para abarcar el 
en el elemento del delito que por antonomasia es privativo de las personas físicas y no de los entes ficticios; pero aún más, en el elemento central de la teoría del delito, respecto del cual, todos los demás constituyen meros predicados.

Efectivamente, si se analiza el concepto de acción desde esta perspectiva, resulta evidente la imposibilidad teórica de imputar responsabilidad penal a una persona jurídica, pero nuevamente, tanto la evidencia práctica, como nuevos desarrollos dogmáticos permiten hacer frente a esta objeción desde varias perspectivas, de las cuales se extraerán únicamente dos que permiten reflexionar sobre este punto. La primera tiene que ver, como se dijo con la evidencia fáctica de que el vertiginoso desarrollo de la ciencia y de la técnica sorprende cada día con la elaboración por ejemplo, de prototipos robóticos dotados cada vez de mayor autonomía, no solo de movimientos sino también de ciertas capacidades de discernimiento, así como la existencia de modelos de ordenadores con inteligencia artificial ${ }^{32}$ capaces de tomar decisiones, muchas de la cuales difícilmente podríamos sostener que no constituyan "actos".

conjunto de análisis que van desde las formulaciones clásicas, en sus versiones naturalista y neokatiana (causalistas), hasta las finalistas con su noción de "acción final", pues todas ellas coinciden en caracterizar a la acción como un acto fundamentalmente humano, para lo cual, tomo como referencia a JESCHECK en su Tratado de Derecho Penal, Parte General, Trad. Miguel Olmedo Cardenete, Quinta edición, Ed. Comares, Granada 2002, pp 209-240.

32 En este sentido puede apreciarse la reducción de la brecha antes infranqueable entre la realidad y la ciencia ficción cinematográfica. Ejemplos de ello son los ya clásicos filmes "Inteligencia Artificial", "Matrix "o "Yo Robot" y últimamente, el interesantísimo "Ella" con la magistral actuación de Joaquin Phoenix, que da cuenta de la increíble capacidad de autonomía y autodesarrollo de un sistema informático, capaz incluso de producirle una decepción amorosa. 
Desde la perspectiva dogmática, conviene referirse a la ya mencionada Teoría de Sistemas de LUHMANN, que bien puede ser criticada por su fundamentación y alcances políticos, pero que constituye lo que se podría considerar como una "buena teoría" para explicar el funcionamiento de las diferentes estructuras sociales, sus nexos de comunicación y sus capacidades de reproducción a partir de lo que se conoce como "autopoiesis", categoría tomada de las investigaciones realizadas por los biólogos chilenos Humberto Maturana y Francisco Varela a inicios de los años setenta del siglo pasado, para explicar la forma de conservación y reproducción de las células vivas. ${ }^{33}$

De acuerdo con esta teoría ${ }^{34}$, la sociedad funciona no tanto como una suma de individuos, sino como un entramado de sistemas complejos que se producen y reproducen a sí mismos, dentro de los cuales se encuentran precisamente las empresas, organizadas o no bajo la figura de personas jurídicas. Estos sistemas generan mecanismos de comunicación que permiten su desarrollo y evolución constante, lo que les permite establecer verdaderos sistemas de toma de decisiones que dan lugar a su vez a sistemas organizativos independientes de sus integrantes (personas físicas), conformando así la denominada "cultura organizacional" que posee una dinámica y valores colectivos propios, articulando mecanismos de identidad, pertenencia y exclusión que vinculan

33 VARElA, Francisco J.; \& MaturanA, Humberto R., De máquinas y seres vivos: Una teoría sobre la organización biológica, Ed. Universitaria, Santiago de Chile, 1973.

34 Las características fundamentales de la Teoría de Luhmann y la autopoiesis han sido tomadas de Gomez-JARA DíEz, Carlos, "Autoorganización empresarial y autorresponsabilidad empresarial", Revista Electrónica de Ciencia Penal y Criminología, 2006, num 8-05, disponible en http:/ / criminet,ugr.es/recpc. 
a sus integrantes, convirtiéndose así en entidades dotadas de verdadera autonomía y capacidad cognitiva, no psíquica (en lo que se diferencian de los seres humanos), pero si organizativa.

Para cumplir con estos ciclos de existencia y desarrollo, realizan operaciones tanto auto como heteroreferenciales, las primeras consistentes en la construcción de programas de decisión que bien pueden analogarse con los planes de vida de las personas físicas, así como vías de comunicación idóneas con otros sistemas para así permitir la realización de tales planes; y las segundas consistentes en las rutinas cognitivas que deben ejecutar para mantenerse interrelacionadas con su entorno, motivándose a su vez y reaccionando frente a las rutinas cognitivas de los otros sistemas sociales, dentro de ellos, el normativo, todo lo cual resulta en una suerte de "conciencia" organizacional que desde una perspectiva constructivista de la personalidad jurídica, reúne todos o casi todos los atributos que se le pueden exigir a una persona física para que adquiera el rango de "persona" en el sentido normativo del término ${ }^{35}$. No debe olvidarse además que incluso a las personas físicas se les exige cierto grado de competencia (imputabilidad) para considerar que aquello que hacen constituye efectivamente un "acto" penalmente relevante.

De lo dicho hasta ahora, resulta entonces que la noción de "acto" de la que parte la teoría estándar del Derecho Penal resulta insuficiente para abarcar los supuestos antes mencionados de la existencia de "máquinas inteligentes" o de "organizaciones

35 Sobre el conjunto de requisitos que un individuo de la especie humana debe reunir para ser considerado "persona" en el sentido normativo del término, véase el artículo de FEINBERG, Joel, "Abortion", disponible en http://www.ditext.com/feinberg/ abortion.html. 
autopoiéticas" como ciertas empresas organizadas bajo la figura de personas jurídicas, cuya "autonomía cognitiva" bien puede desembocar en la realización de auténticos actos penalmente relevantes, encontrándose en este sentido satisfecha la exigencia constitucional en cuanto a la imputación de responsabilidad penal a las personas jurídicas.

Esto tiene a su vez consecuencias respecto de las otras exigencias constitucionales, pues a partir del reconocimiento como entidades competentes a las organizaciones autopoiéticas, se puede aceptar sin dificultades que sus actos pueden ocasionar daños a terceros desde una perspectiva penal (principio de lesividad) ${ }^{36}$; así como de que en consideración a su capacidad cognitiva autónoma, que las convierte en "entes no triviales", dotados de una suerte de "conciencia propia", se pueda fundar juicios de culpabilidad por el cometimiento de esos actos (principio de culpabilidad), observando desde luego los requisitos tanto procedimentales como sustanciales para la construcción de tales juicios; más todavía si como se dijo, aún las teorías de la culpabilidad tradicionales excluyen de los juicios de atribución penal a determinados individuos (los inimputables), precisamente porque no reúnen las exigencias normativas que el ordenamiento jurídico impone para que pueda hablarse de verdaderos "sujetos de imputación penal".

Por último, la exigencia de ultima ratio puede también encontrarse satisfecha si se considera que la extensión de tal principio supone que se encuentren alcanzadas por el Derecho

36 Desde el punto de vista de la responsabilidad objetiva, nadie discute la posibilidad de imputar responsabilidad por daños a las personas jurídicas. 
Penal aquellas conductas -que como se ha visto, bien pueden ser cometidas por las personas jurídicas- estrictamente necesarias para precautelar bienes jurídicos básicos de una sociedad histórica y culturalmente determinada, aunque se reconoce que efectivamente resulta problemático conciliar la necesidad de una mínima intervención penal con los criterios de imputación expuestos, pues los mismos se encuentran basados en supuestos hipotéticos y de ocurrencia futura, como los planteados tanto en los avances científico-técnicos a los que se ha aludido, así como en los de estructuras organizativas autopoiéticas, que solo podrían verificarse en grandes complejos empresariales, donde tanto la composición accionaria, como la diversificación del trabajo y fundamentalmente, la toma de decisiones se encuentre suficientemente diversificada.

Por todo lo expuesto, se considera que a pesar de algunas tensiones con los principios fundamentales antes analizados, la responsabilidad penal de las personas jurídicas en términos generales no es contraria a los presupuestos de un Derecho Penal compatible con el estado constitucional de Derecho, aspecto que sin embargo, se encuentra condicionado por el modelo de imputación que se utilice y al respecto, conviene analizar los diferentes diseños que conoce la doctrina contemporánea.

El primer modelo conocido es el denominado "modelo de transferencia", que básicamente consiste en la posibilidad de sancionar a la persona jurídica por aquellos actos cometidos por sus socios, representantes legales o administradores, ya sea que las actividades ilícitas de la persona física se realicen a nombre o por cuenta de la persona jurídica o que de ellas resulte un 
beneficio para la misma ${ }^{37}$. Como puede apreciarse, un modelo de estas características presenta múltiples problemas, aún partiendo de la atípica forma de imputabilidad de la persona jurídica que aquí se ha propuesto y que dichos problemas se presentan tanto en el orden constitucional si se lo analiza a la luz a los principios de acto, lesividad y culpabilidad antes expuestos; así como en el dogmático, si se lo analiza desde las categorías de la causalidad, culpa y autoría, así como desde las finalidades mismas de la pena.

Frente a este estado de cosas, surge el modelo denominado de "culpa por organización" o más propiamente, de "culpa por defecto de organización”, que formula la posibilidad de sancionar a la persona jurídica por actos cometidos en su propio beneficio o realizados por las personas físicas que actúen en su representación, teniendo siempre como presupuesto, las deficiencias verificadas en su estructura organizativa para prevenir, controlar y sancionar actos delictivos que puedan cometerse en el desarrollo de sus actividades, convirtiéndose este defecto de organización en un elemento normativo que opera como "presupuesto de la responsabilidad penal" 38 , cuya función es racionalizar el ejercicio del ius puniendi. A partir de esto se establece la necesidad entonces de prevenir y corregir los defectos de organización, para lo cual, las empresas pueden o deben -y este será precisamente el dilema a resolver- elaborar planes de cumplimiento normativo, denominados compliance de acuerdo con el término anglosajón

37 Sobre el "modelo de transferencia" puede consultarse una explicación muy didáctica en CASAS, Ismael CLEMENTE y Álvarez FEIJO, Manuel. "Sirve de algo un programa de compliance penal?", Revista electrónica Actualidad Jurídica Uria Menéndez / 28-2011.

Bacigalupo, Enrique. Op. Cit. pp. 129. 
aplicado para este propósito, luego de los casos emblemáticos a los que se ha hecho alusión.

El modelo de culpabilidad por organización aparece entonces como más compatible con los principios constitucionales del Derecho Penal en un estado constitucional, así como con las categorías dogmáticas de la Ciencia Penal estándar, pues es el único que posibilita una lectura "conforme a la constitución" 39 de las normas que regulan la responsabilidad penal de la persona jurídica, al tiempo que es el único que permite fundar tanto el juicio de reproche penal por actos cometidos por "otros", como los socios, administradores, empleados, etc, con lo cual se podría satisfacer el fundamento de la culpabilidad y explicar la función preventiva de la pena, de manera coherente con el principio de mínima intervención o ultima ratio del Derecho Penal, partiendo de la premisa -y aquí se acude a categorías de la imputación objetiva- de que el déficit de controles adecuados en la estructura de la empresa ocasione el incremento del riesgo permitido. Pese a la aparente suficiencia explicativa de este modelo, pocos han sido los ordenamientos jurídicos que se han ocupado de hacer explícita su adopción, aspecto del que a fuerza de necesidad se ha ocupado más bien la jurisprudencia y la doctrina. ${ }^{40}$

39 La interpretación conforme a la Constitución forma parte del "Principio de Conservación del Derecho" que a su vez garantiza un adecuado equilibrio entre la regla de mayoría y el principio contramayoritario.

40 Excepción hecha de las leyes penales italiana y chilena que como consecuencia de su aplicación han llegado incluso a formular la obligatoriedad del compliance y aún, a regularlo exhaustivamente. 


\section{DEFINICIÓN Y FUNCIONES DEL COMPLIANCE.}

Como se anticipó, el término compliance es un anglicismo que a pesar de su uso creciente en el mundo de la empresa, no se encuentra todavía oficialmente contemplado por la Real Academia de la Lengua Española ${ }^{41}$ y ello posiblemente obedezca a que la noción del compliance ofrece varias dificultades, la primera de ellas desde su traducción al español, que en términos generales sería la de "cumplimiento" o "conformidad" 42 , que aplicada al ámbito jurídico sería "cumplimiento del derecho" o "cumplimiento de las normas". Otra de las dificultades es que constituye un término polisémico, cuyos distintos significados pueden rastrearse en disciplinas como la medicina por ejemplo, donde desde hace mucho tiempo se lo entiende como la adecuación de los procedimientos médicos a los respectivos protocolos que conforman la lex artis; y en el ámbito del managment como una estrategia de buenas prácticas empresariales ${ }^{43}$. Desde una perspectiva jurídica, pero que necesariamente debe contemplar una visión transdisciplinaria, la noción de cumplimiento del Derecho aludida tiene que ver también con aspectos como la elaboración de programas de autorregulación empresarial que propendan a la denominada due diligence, como instrumento de valoración de empresas que cotizan en mercado de valores, por ejemplo; o en general, con parámetros de evaluación por parte de quienes hacen negocios con empresas, donde finalmente se ha incorporado también al

41 Real Academia Española, Diccionario de la Lengua Española, $22^{\circ}$ publicación, 2001, disponible en http://www.rae.es/recursos/ diccionarios/drae.

42 Sobre esta noción, véase Bock, Dennis, "Compliance y deberes de vigilancia de la empresa", en Compliance y Teoría del Derecho Pena". AAVV, Marcial Pons, Madrid, 2013, p. 107

43 Revista "Compliance insider", num. 8 enero 2014, p. 10. 
estado, en tanto se constituye en un importante agente económico, ya sea por su intervención directa en la economía o por ser el mayor requirente de bienes y servicios que son provistos por las empresas y en tal sentido, se han generado también políticas de evaluación de esta due diligence por parte de organismos multilaterales de financiamiento como el Banco Mundial ${ }^{44}$ o el Banco Europeo de Inversiones ${ }^{45}$, en forma previa a validar los proyectos presentados por los estados, así como a efectuar el desembolso de los créditos; construyendo una práctica que se ha dado en llamar "gobernanza global" o global law.

En el compliance así entendido, deben considerase aspectos tales como la legislación en sus diferentes ámbitos de regulación, como prevención riesgos laborales, protección datos, blanqueo capitales, derecho de la competencia, mercado de valores, etc, que conforman un entorno normativo denominado como "autorregulación regulada"; así como deben considerarse también reglas sobre el buen gobierno corporativo donde se contemplen controles gerenciales y administrativos de arriba hacia abajo y viceversa; códigos éticos relacionados con la lucha contra la corrupción, responsabilidad social, auditorías y certificaciones de calidad; y, finalmente, comprende también la responsabilidad penal de la persona jurídica, como corolario de todo lo anterior, cuya existencia constituye de por sí un sistema de heteroregulación propiamente dicha ${ }^{46}$, aunque matizada luego precisamente por

44 Banco Mundial, "Guidelines on preventing and combating fraud and corruption in program for results financing", febrero de 2012, tomado de Nieto Martin, Adán, “Problemas fundamentales del cumplimiento normativo en el Derecho Penal", VV.AA, Compliance y teoría del Derecho Penal, Marcial Pons, Madrid, 2013, p. 23.

Banco Europeo de Inversiones, Guide to Procurement, octubre de 2001, tomado ibid.

46 En todo esto, se sigue el esquema propuesto por NiETO MARTín, 
la función del compliance, dando lugar a un sistema que bien podría designarse como "autorregulación heteroregulada".

Como podrá apreciarse, el alance de las nociones del compliance es diverso, según se trate del ámbito normativo al que se lo aplique, sin embargo, para los efectos de analizar la responsabilidad penal de la persona jurídica, algunos autores hablan de la necesidad de un compliance penal específico ${ }^{47}$ que contemple entre otros elementos, mecanismos de prevención, control y sanción de ilícitos estrictamente penales como los relacionados con el lavado y blanqueo de dinero, la corrupción entre particulares y los delitos bancarios, societarios, bursátiles y ambientales. Otros autores sin embargo, consideran que una vez estructurados los programas de compliance relacionados con las buenas prácticas en general, resulta innecesario hablar de una forma más (criminal compliance) sino que simplemente debe efectuarse una lectura y organización de los mismos pero en clave del Derecho Penal. ${ }^{48}$ Particularmente se considera que esta resulta la posición más acertada si se tiene presente que existe una necesaria relación entre los programas de cumplimiento normativo y todo el entramado de actividades empresariales, así como la necesaria vinculación que tiene la prevención de riesgos de responsabilidad penal con otros riesgos de responsabilidad normativa propios de otras áreas del Derecho, a las que el Derecho Penal económico remite constantemente.

Adán, Op. Cit., pp. 23-26.

47 Entre los autores que abogan por la construcción de programas de tal naturaleza podemos encontrar a BACIGALUPO, TIEDEMANN y RoTSCH, bajo cuya dirección incluso existe en la Universidad de Ausburgo el Centre for Criminal Compliance

48 Partidarios de esta tesis son el mismo Nieto Martín, Mir PUIG y Silva SÁNCHEZ. 
Establecida de esta forma la definición y alcance del compliance, es necesario entonces analizar cuál es su función dentro del sistema de responsabilidad penal de la persona jurídica, tarea para la cual resulta indispensable en primer lugar, ubicar en qué aspecto de la teoría del delito se sitúa el que hasta hoy hemos denominado "modelo de imputación de la culpa por defecto de organización”, pues se considera que solo a partir de ello se puede buscar la justificación funcional del compliance, así como las consecuencias de su inaplicación o deficiente ejecución. Al respecto podemos apreciar que este constituye uno de los debates contemporáneos más necesarios, pues la doctrina no ha profundizado y mucho menos ha llegado a un acuerdo sobre el status de tal "modelo de imputación". Particularmente se considera que el mismo puede analizarse desde el injusto penal, ya sea como elemento normativo del tipo; o desde la culpabilidad como consecuencia estructural de la defectuosa capacidad de la persona jurídica de motivarse frente a la norma; o finalmente, desde la punibilidad como un requisito objetivo de ésta.

En tanto elemento normativo del tipo penal se puede sostener que la referencia al "defecto de organización" efectivamente remite a un concepto jurídico valorativo que proporciona sentido a la descripción de la conducta antijurídica ${ }^{49}$, condicionándola de tal manera que frente a su ausencia, el hecho imputable a la persona jurídica quedaría fuera del ámbito de la antijuridicidad ${ }^{50}$; es decir,

49 Jescheck, Hans-Heinrich, “Tratado de Derecho Penal Parte General", Comares, $5^{\circ}$ edición, Granada, diciembre 2002, p. 289, quien a su vez toma estas nociones de elementos normativos del tipo, de Engisch Mezger y Schluchter

50 En este sentido se adopta la noción de "Tipo" como "tipo de injusto" y desde una perspectiva material que supera la definición puramente formal de BELING y resulta más cercana a posturas como las de 
en caso de verificarse que no existió el defecto de organización, especialmente por la existencia y cumplimiento de un programa de compliance, entonces no se encontraría acreditado este elemento normativo del tipo penal y el hecho atribuido a la persona jurídica no sería típicamente antijurídico.

Se puede sin embargo, contraponer como objeción sólida a este argumento el hecho de que los elementos normativos del tipo penal, así como los descriptivos y aún los subjetivos, deben encontrarse explícitamente contemplados en la norma, para de esta manera cumplir con el subprincipio de lex scripta del principio de legalidad y esto lamentablemente no ocurre en la gran mayoría de leyes que instauran la responsabilidad penal de las personas jurídicas sino que por el contrario, el modelo de imputación de la culpa por defecto de organización ha sido más bien una construcción pretoriana y aunque se reconoce que en muchos casos la valoración sobre la existencia o no de los elementos del tipo penal se encuentra librada a la tarea de determinación de los jueces, debido a la inevitable apertura del lenguaje jurídico, asumir en abstracto una justificación como esta, sería incompatible con la necesidad de insistir en la mayor taxatividad posible de las leyes penales en consideración a dos aspectos fundamentales: la importancia de los derechos que se encuentran en juego y la necesidad de controlar el poder punitivo del estado, que en tanto poder, tiende siempre a conservarse y expandirse.

Desde el punto de vista de la culpabilidad, ya sea que se adopten criterios subjetivistas, normativistas o funcionalistas

Hergler, Sauer, Mezger y Wolf. 
de la misma ${ }^{51}$, lo cierto es que con ciertas reformulaciones, las categorías de "libertad de voluntad" y "exigibilidad del comportamiento conforme a Derecho" 52 han sido estables o en su defecto, inevitables para todos los ámbitos de la doctrina que se han ocupado de ella, desde las nociones originales de libre albedrío hasta las de instrumento necesario para el cumplimiento de los fines de prevención general de la pena, pero más todavía si se la considera como elemento fundamental para la regulación del poder punitivo dentro de un estado constitucional, donde se ha reivindicado a la autonomía como fuente tanto de derechos como de obligaciones y en este último sentido, la exigibilidad prima facie de que todas las personas se motiven frente a las normas penales, cuya transgresión implica un reproche legítimo, salvo por las excepciones conocidas de incapacidad, error o exculpación.

Aplicando estos criterios a la responsabilidad penal de la persona jurídica, el rol del compliance bien podría ser equiparado a esas pautas de comportamiento conforme a Derecho que se exigen a las personas físicas como presupuesto de la culpabilidad y al defecto de organización, precisamente como esa deficiente capacidad de motivación frente a las normas, que puede ser evaluada de

51 Como precursores de la teoría subjetiva se pueden citar a Von LiTZBELING, entre los normativistas, a una amplia gama de autores, siendo los más relevantes FranK, KOHLRAUSCH, Welzel, HiRSCH y STRATENWERTH; y entre los funcionalistas desde luego, Roxin, JAKOBS y ROTH.

52 Tomo en esta parte las expresiones de PASTOR R, Daniel, "La discusión actual en torno de la culpabilidad", en Problemas actuales de la Parte General del Derecho Penal, VV.AA, Ad Hoc, Buenos Aires, noviembre de 2010, pp.614-617 donde distingue el alcance político de la expresión "libertad de voluntad", del meramente natural "libertad de acción". 
manera así mismo análoga a la forma en que se lo hace con la libertad de voluntad para construir el juicio de reproche propio de la culpabilidad.

Podrían asumirse como condición objetiva de punibilidad tanto el defecto de organización como el compliance, si se considerase que nada aportan ni al injusto penal ni a la culpabilidad de la persona jurídica, ya sea porque los mismos se consideren suficientemente acreditados, el primero por las referencias típicas constantes en las normas penales que establecen dicha responsabilidad realizadas ya sea con dolo o con imprudencia; o porque la obligación de comportarse conforme a Derecho se encuentra derivada de otras normas del ordenamiento jurídico, especialmente de carácter constitucional y por ello resulte sobreabundante elaborar otro tipo de normas y mucho menos provenientes de un sistema de autorregulación como el compliance, pero que sin embargo de ello, sea necesario acudir a estos dos conceptos (defecto de organización y compliance) exclusivamente con propósitos instrumentales que permitan compatibilizar la necesidad de responsabilizar penalmente a las personas jurídicas con los principios de aplicación del Derecho Penal en el estado constitucional, de lo que se sigue que en caso de ausencia de tal defecto de organización no sería posible la imposición de pena. Como se verá, dentro de esta concepción, la función del compliance sería meramente contingente, pues bastaría con que se acredite el defecto de organización por cualquier otro medio para que se considere satisfecha la condición objetiva de punibilidad.

Finalmente, desde la teoría de la imputación objetiva podría también considerarse al defecto de organización como un caso prototípico de incremento del riesgo permitido cuya constatación 
permitiría atribuir "objetivamente" el resultado a la persona jurídica y fundar de esta manera la caracterización del injusto penal. Bajo esta perspectiva, la función del compliance bien podría ser la de delimitar ese riesgo permitido en base a los materiales normativos y organizativos proporcionados por el principio de confianza ${ }^{53}$.

En el mismo sentido, podrían considerarse como funciones tanto del compliance como del defecto de organización, convertirse en los pilares sobre los que puede construirse satisfactoriamente la tan anhelada normativización de la imputación objetiva, que permita superar la noción eminentemente causalista representada fielmente por el modelo de transferencia, criticado por otras razones en páginas anteriores.

Cualquiera sea la función que tenga el compliance en la Teoría del Delito, resulta indispensable llamar la atención en el sentido de que su presencia incide definitivamente en la denominada Teoría del Error, pues acarrea consecuencias como limitar y de manera significativa, la posible discusión acerca del error de tipo o del error de prohibición, haciendo poco probable que cualquiera de ellos pueda reunir la condición de invencible, con los efectos que de ello se siguen igualmente en los ámbitos de la tipicidad, la culpabilidad o la imputación objetiva.

53 JaKoBs, Gunther, La Imputación Objetiva en Derecho Penal, Trad. Manuel Cancio Meliá, 4ta. reimpresión, Ad Hoc, Buenos Aires, junio de 2009. 


\section{PROBLEMAS DEL COMPLIANCE FRENTE A LA TEORÍA PENAL ESTÁNDAR:}

Como se ha visto, tanto la noción misma del compliance, como su ubicación en la teoría del delito y sus funciones son de por sí problemáticas y a ello se suman a su vez, problemas relacionados con diversos ámbitos del Derecho Penal General y también con el Derecho Penal Económico en particular, que tienen que ver principalmente con aspectos como como causalidad, autoría y participación; o, con las finalidades de la pena, cuyo tratamiento desde las categorías tradicionales de la dogmática penal parece insuficiente y su análisis corresponde a una pretensión investigativa mucho más exhaustiva, que supera los objetivos del presente trabajo.

Sin perjuicio de ello y dado que se considera que una profundización teórica acerca de las insuficiencias de la teoría estándar satisface inquietudes estrictamente académicas cuyo objetivo final sería precisamente demostrar tal insuficiencia, se considera que desde una perspectiva igualmente académica pero mucho más instrumental, es posible evaluar algunos problemas del compliance con miras a establecer tanto su fundamentación como su necesidad al momento de analizar la responsabilidad penal de la persona jurídica; propósito para el cual se ha elegido como marco conceptual a la Teoría de la Imputación Objetiva y dentro de ella, se han seleccionado a su vez, dos problemas puntuales, el primero relacionado con la noción de riesgo permitido y el funcionamiento del principio de confianza; y el segundo, referido a la posición de garante.

En cuanto al primer problema, como se sabe, la Teoría de la Imputación Objetiva fundamenta el contenido del injusto penal 
a partir de la noción de riesgo permitido y más precisamente, de la creación de un riesgo jurídicamente desaprobado cuya determinación se hace acudiendo al ámbito de protección de la norma penal, que a su vez es necesario buscar en la manera en que las sociedades histórica y temporalmente determinadas establecen el grado de aceptación o repudio de ciertas conductas, que por el hecho mismo de ser sociales, es decir, intersubjetivas, implican riesgos, que según lo expuesto, serán permitidos o no permitidos (vale decir, desaprobados); de ahí que se vuelve indispensable para analizar el riesgo desaprobado -o dicho de otra forma, el incremento del riesgo permitido-, analizar correlativamente la forma en que opera el principio de confianza.

Pasando por alto la discusión existente sobre si el principio de confianza es solamente una especie del género riesgo permitido o si por el contrario, mantiene alguna autonomía conceptual, lo que aquí interesa es asumir que dicho principio supone que todos los participantes de la práctica y en este caso, de las prácticas empresariales tienen una expectativa razonable de que sus pares actuarán de manera responsable y conforme a las normas, mucho más si se tiene en cuenta que generalmente son agentes económicos altamente competentes, lo que nuevamente plantea el dilema de la autoregulación o la heteroregulación, que se encuentra fuertemente condicionado por aspectos políticos e ideológicos que definen el modelo de estado.

Por una parte, si se trata de estados de corte más liberal, se tendrá que el principio de confianza y consiguientemente, el ámbito del riesgo permitido deberán rastrearse en normas de autorregulación (si acaso existen) de las empresas, donde los partícipes de las prácticas económicas tienen un campo de acción más flexible, que encuentra por supuesto sus límites en las prohibiciones 
contempladas en las normas penales; y por otra, en estados más intervencionistas, tanto el principio de confianza como el riesgo permitido estarán sometidos a una intensa actividad reguladora estatal (heteroregulación), donde cobra mayor importancia la necesidad de programas de cumplimiento normativo (compliance) para delimitar el ámbito de desenvolvimiento del principio de confianza, así como para fijar el entorno de los riesgos permitidos que posteriormente permitan analizar la existencia o no de defectos de organización frente a la amplia gama de normas jurídicas regulatorias hetero impuestas y dentro de ellas, las normas de prohibición penal. En cualquiera de los dos casos el compliance aparece efectivamente como necesario, en el primero dado que la mayor libertad de acción exige igualmente mayor grado de responsabilidad, no solo por exigencias de tipo moral, sino también porque será correlativamente mayor el margen de discrecionalidad de los jueces para definir aspectos como el incremento y realización de los riesgos permitidos; y en el segundo, dado que el efecto intimidatorio que pueda ejercer un entorno de controles asfixiante exige que las empresas adopten recaudos para prevenir y eventualmente enfrentar los elevados riesgos de responsabilidad normativa.

Desde otro punto de vista, si bien lo afirmado puede resultar fácil de asimilar, no parece serlo en cambio la relación existente entre principio de confianza y compliance, pues si aquel se asume en un sentido fuerte, resulta entonces contradictorio agregar al sistema normativo estatal uno adicional autoregulado -que eso viene a ser el compliance- pues ello supone más bien un debilitamiento de tal principio de confianza en la medida que al imponérsele mayores regulaciones, lo que se está enviando es precisamente el mensaje contario, esto es, que existe un grado de desconfianza en la actuación de los partícipes de la práctica 
jurídico-económica, teniendo entonces que para la gran mayoría de actividades sociales basta que el principio de confianza y los riesgos permitidos sean establecidos en las normas jurídicas que establecen sus límites, pero en el caso de la responsabilidad penal de las personas jurídicas sea necesario que esas normas se encuentren complementadas con otras de propia generación empresarial (compliance), más todavía si se tiene presente que para su implementación es necesaria la intervención de actores independientes, denominados compliance officers. Particularmente se considera que ambos postulados no son incompatibles y que por el contrario, es perfectamente posible superar la dicotomía auto-heteroregulación por un modelo ecléctico que bien podría denominarse de "co-regulación" 54 que permite un funcionamiento coordinado de ambas esferas regulativas con el objeto de alcanzar una mejor determinación de los ámbitos del principio de confianza y el riesgo permitido.

No puede dejarse de mencionar que para resolver esta aparente contradicción en la relación entre el principio de confianza y compliance puede también acudirse a la teoría de los "riesgos especiales" 55 , de acuerdo con la cual, las actividades de empresariales se adecuan a esta categoría, dadas sus particulares organizativas que implican una bien definida distribución del trabajo y de roles; así como sus objetivos concretos de obtención de lucro, para lo cual deben acudir a estrategias de mercado que les permitan ampliar su presencia y eliminar competidores, todo

54 Denominación que se toma de KuHLEN, Lothar, "Cuestiones fundamentales de compliance y Derecho Penal", en Compliance y teoría del Derecho Penal, VVAA, Marcial Pons, Buenos Aires, 2013, pp. 67-68

55 SILVA SÁNCHEZ, Jesús María, Deberes de vigilancia y compliance empresarial, op. cit., pp.85-86. 
lo cual genera una suerte de ambiente criminógeno propicio para la gestación, aprendizaje y reproducción de actividades ilícitas, tesis que a su vez tiene inspiración en estudios criminológicos como los de Sutherland, con sus teorías de la Asociación Diferencial ${ }^{56}$ y de la "delincuencia de cuello blanco".

Una aplicación de la teoría de los riesgos especiales a la empresa considera que en presencia de estructuras organizadas que presentan elementos criminógenos como los descritos, decae el principio de confianza y se modifican las esferas de competencia de los individuos y en este caso, aún de la propia persona jurídica, las mismas que deben interactuar en base a dos deberes: uno de conocimiento de los actos y de prevención de las omisiones de terceros relacionados con la actividad de la empresa; y otro, de intervención en las esferas de competencia de esos terceros, con el objeto de evitar la producción de resultados lesivos o peligrosos a partir de sus actos u omisiones. Como se verá, asumir una tesis de estas características implica repensar casi por completo el contenido y funciones de las categorías estándar no solo del principio de confianza, sino además, de la responsabilidad por actos de otros, así como de los deberes de evitación y de competencia de la víctima, especialmente en la modalidad de la omisión. Sobre esto último, se puede afirmar que dada la menor complicación dogmática que representan los delitos comisivos dolosos bien pueden considerarse a ellos como el grupo de "casos fáciles" y los delitos omisivos imprudentes en cambio como el grupo de "casos difíciles", donde resalta como especialmente problemática la posibilidad de derivar responsabilidad dolosa de la persona jurídica en los casos de defecto de organización

56 Sutherland Edwin, Principios de Criminología, Chicago University Press, Chicago, 1924 
o incumplimiento de programas de compliance por actuación imprudente de los administradores.

Dos posibles objeciones que puedenhacerse a la aplicación de la teoría de los riesgos especiales son: en primer lugar, que preconcebir a la empresa como una estructura ontológicamente peligrosa presenta problemas de orden constitucional relacionados con los principios de igualdad y presunción de inocencia; y en segundo lugar, que existen también problemas de justificación del argumento al asumir de partida el peligro especial que caracterizaría a la actividad empresarial, pues ello constituye una falacia de petición de principio, donde se presupone aquello que se quiere demostrar, que en este caso es justamente la razón por la que es necesario reformular el contenido del principio de confianza.

El segundo problema a analizar tiene que ver con la posición de garante que asumen tanto la persona jurídica como sus propietarios, administradores y aún más, el denominado compliance officer como delegado por la administración para realizar tareas de seguimiento y control de la ejecución del programa de compliance. Al respecto, son varios los sub problemas que pueden formularse, de los cuales se extraerán tres: el primero relacionado con la justificación de la posición de garante en cabeza de tales individuos; el segundo con la naturaleza de los deberes asumidos por quienes ostentan la posición de garante; y el tercero, con la posibilidad de delegación de tales deberes hacia terceros denominados compliance officers. Finalmente se analizarán las posibles tensiones que podría ocasionar la ejecución del compliance con la garantía de derechos y principios constitucionales fundamentales de protección a los trabajadores. 
En cuanto a lo primero, bien podría sostenerse de inicio, que establecer una posición de garante en cabeza de los propietarios, administradores o aún de terceros relacionados con el cumplimiento de las normas que regulan la actividad empresarial puede resultar sobreincluyente pues lo que verdaderamente se está haciendo es asignar de manera genérica obligaciones de control y vigilancia a determinadas personas por lo que hacen o dejan de hacer otras personas, quienes además y esto es determinante, son autorresponsables ${ }^{57}$, lo que supondría desconocer precisamente el principio de autorresponsabilidad, así como el de competencia, éste último entendido desde el ámbito de separación absoluta de esferas competenciales específicamente para el campo del Derecho Penal, donde se busca que tales esferas interactúen exclusivamente a través de los deberes de solidaridad; lo cual no ocurre en otros ámbitos del Derecho y de la vida social, donde resulta incluso deseable que las esferas de competencia individual compartan la mayor cantidad de relaciones posibles.

Resulta entonces necesario encontrar una justificación para que esto funcione distinto en los casos de responsabilidad penal de las personas jurídicas y parecería ser que la teoría de los riesgos especiales a la que se aludió antes proporciona una explicación plausible en el sentido de que puede deducirse sin problemas de la noción de que las actividades empresariales constituyen en sí riesgos especiales, el hecho de que a su vez existan deberes especiales en cabeza de quienes tienen a su cargo la propiedad

57 Aclaración que resulta necesaria pues la doctrina conoce y acepta de manera casi unánime casos donde a ciertas personas se les impone deberes especiales de cuidado respecto de bienes o de otras personas pero que son inimputables. Al respecto, SCHUNEMANN, Unternehmenskriminalitat und Strafrecht, Colonia, 1979, pp. 101 y ss. Citado por Silva Sánchez, op. cit., p. 83. 
o administración, quienes al adquirir conocimiento de hechos defectuosos o potencialmente dañosos, tienen la obligación de intervenir en la esfera de competencia de quienes los están realizando y tienen el deber de impedirlos (lo que constituiría el incremento del riesgo permitido) para de esta manera evitar su realización.

Una justificación como esta, si bien supera los estándares de capacidad explicativa y de atractivo intuitivo, parte sin embargo de caracterizar a la empresa como genéticamente peligrosa, asunción que fue objetada antes por la tensión que podría presentar con los principios constitucionales de igualdad y presunción de inocencia, al que además se puede agregar ahora el de daño, lo cual resulta particularmente interesante en este punto, pues nuevamente, se estaría produciendo una mera transferencia de responsabilidad penal ajena hacia personas que si bien tienen deberes de orden laboral como la vigilancia y control, no deberían por ello ser sobreexigidos con la amenaza de sanciones penales por ese incumplimiento; al tiempo que existen buenas razones para sostener la implausibilidad moral de tal sobreexigencia ${ }^{58}$.

Frente a ello, una posible justificación de la asignación de esta posición de garante en cabeza de los propietarios, administradores o aún, de los compliance officers podría encontrarse más bien en la aplicación normativa de un ejercicio de ponderación entre principios y derechos, según el cual, una ampliación de las nociones

58 Al respecto, en la Filosofía Moral son múltiples los debates sobre los denominados "deberes positivos" o también conocidos como "deberes de buen samaritano", donde la obligación de sacrificarse en beneficio de otros encuentra sus límites en el cuidado de la propia vida, noción que bien podría extenderse también al de la propia libertad personal. 
tradicionales de la posición de garante resulta equivalente a la necesidad de protección de otros derechos y más concretamente, bienes jurídicos como los que se pretende resguardar imponiendo deberes especiales a individuos que encontrándose previamente advertidos, se colocan voluntariamente en tal posición de garante (competencia por asunción) y reciben como contraparte ya sea las utilidades que reporta la actividad empresarial o una remuneración que se fija precisamente en orden al grado de responsabilidad y consiguientes riesgos que asumen.

En el mismo orden de alcanzar una justificación más acabada sobre estos deberes especiales, algunos autores han intentado diferenciar la naturaleza de ellos, para lo cual los han divido en deberes de protección y deberes de vigilancia, convirtiendo a los obligados por tales deberes respectivamente en "garantes de protección" o "garantes de vigilancia" 59 , donde los casos paradigmáticos del primer tipo de garantes son los médicos que tienen a su cargo la protección de la vida y la salud de sus pacientes, de manera directa; y el segundo tipo de garantes tienen en cambio a su cargo la vigilancia de la tutela de otros derechos y bienes jurídicos, pero de manera indirecta o a través de estructuras organizativas con una estricta asignación de roles y división del trabajo, como en el caso de las actividades empresariales. Esta tesis ofrece el problema de que no existen criterios materiales que permitan fundar esta distinción, razón por la que se abre la posibilidad de la excesiva discrecionalidad al momento de caracterizar la posición de garante de una u otra manera, según se decida si lo que se están exigiendo son deberes de protección o de vigilancia.

59 Kaufmann, Armin, Dogmática de los delitos de omisión, trad de la $2^{\circ}$ edición de Cuello Contreras/Serrano González de Murillo, 2006, pp. 297. 
El tercer aspecto a tratar se relaciona con la posibilidad de delegación de los deberes de vigilancia y control de los propietarios y administradores de las personas jurídicas a actores independientes (complience officers) lo cual ofrece al menos dos interrogantes: 1. ¿es posible delegar la posición de garante? y 2. En el evento de aceptarse la posibilidad de la delegación ¿cuáles son sus alcances?

Sobre la primerainterrogante, loquese discutees la fundamentación penal de una posible delegación de responsabilidad, bajo la premisa tradicional del carácter "personalísimo" y por lo tanto, indelegable de la responsabilidad penal. Existen sin embargo posiciones superadoras de este aparente dilema que sugieren la posibilidad de encontrar la fundamentación no de la delegación de la responsabilidad penal, sino de los deberes de control y vigilancia de las actividades empresariales, cuya naturaleza es extrapenal, en normas y principios generales del Derecho que posibilitan tal delegación ${ }^{60}$, en cuyo caso los terceros delegados (compliance officers) adquieren la posición de garante mediante la figura de competencia por asunción, teniendo presente que generalmente en los delitos omisivos e imprudentes, tanto el dominio de la fuente de peligro, como los deberes de evitación de la realización de ese peligro provienen también de normas extrapenales (lex artis). Diferente es que se indague sobre la legitimidad de una eventual transferencia de responsabilidad penal propia de los propietarios o administradores hacia los compliance officers, así como sobre la necesidad de limitar el eventual exceso punitivo que pudiera suponer la imposición de sanciones tanto al delegante como al delegado de la posición de

60 Bermejo, Mateo G./ PAlermo, Omar, La intervención delictiva del compliance officer, Marcial Pons, Buenos Aires, 2013, p. 180. 
garante, para lo cual serán necesarios algunos criterios que se analizarán al responder la segunda interrogante.

Precisamente sobre este segundo aspecto, una vez aceptada la posibilidad de delegación de la posición de garante, corresponde delimitar el alcance de la responsabilidad penal de los compliance officers y para el efecto se considera que pueden ser útiles dos criterios, el primero relacionado con la teoría del dominio del hecho y el segundo, con la definición específica de su esfera de competencia. El primer criterio como se verá tiene relación con la participación del compliance officer en la conducta ilícita, aspecto que se analiza dentro del juicio de culpabilidad, donde habrá que determinarse en cada caso concreto la real capacidad de evitación del ilícito que puede exigirse a este tipo especial de garante, con lo que se abre una gama de posibilidades de atribución de responsabilidad penal, ya sea como autor o partícipe, donde a su vez surgen problemas como la autoría mediata (autor detrás del autor) o la aplicabilidad de la teoría del rol indiferenciado de omitente, según la cual en los delitos de omisión es irrelevante discutir sobre la distinción entre autor y partícipe ${ }^{61}$.

El segundo criterio en cambio se puede analizar desde la perspectiva del injusto (antijuridicidad), a partir de que si bien se puede aceptar esta condición especialmente riesgosa de la actividad empresarial y también la obligación del compliance officer de ampliar su esfera de competencia y asumir deberes de conocimiento e intervención en esferas de competencia ajenas, es necesario delimitar el campo de acción de dicha esfera de

61 El autor más representativo de esta teoría es Roxin, Autoría y dominio del hecho en Derecho Penal, $6^{\circ}$ ed., 1998, p. 515, aunque reconoce alguna excepciones a esta regla. 
competencia asumida, restringiéndola a la obligación de "dar conocimiento" a la administración de los hechos detectados, siendo éste por tanto el estricto ámbito de su intervención; limitación que impide entonces cualquier tipo de transferencia automática e indebida de la responsabilidad penal que conserva el propietario o administrador delegante de los deberes de vigilancia y control en cuanto a la ejecución de los programas de compliance, con lo cual se ha conseguido también el deseable objetivo de racionalizar el ejercicio del poder punitivo estatal.

Nada de lo enunciado hasta aquí pretende erigirse como solución acabada a los innumerables problemas que apenas se dejan enunciados y que demandarán sin lugar a dudas mayores y más profundas investigaciones, pues como se aprecia, la formulación de justificaciones y soluciones plausibles lo único que hace es abrir nuevas posibilidades de objeciones o conllevan la reformulación de las categorías dogmáticas estándar, al punto de quedar la duda de si tales replanteamientos no constituyen más bien una desnaturalización del sentido con el que se formularon.

Un problema final del compliance tiene que ver con aspectos que trascienden la mera discusión dogmática, en la que se ha pretendido enfatizar para ubicarse en el debate de aspectos relacionados con la aplicación de principios fundamentales del estado constitucional mismo y que por tanto, no pueden quedar fuera del presente trabajo, aunque no sea sino con carácter ilustrativo y se encuentra relacionado con el alcance de los programas de compliance que eventualmente pueden comprometer derechos laborales u otros derechos como la privacidad o el libre desarrollo de la personalidad de los trabajadores sometidos a investigaciones internas (whistleblowing), donde el verdadero peligro es que se produzca una expropiación del monopolio 
estatal de la investigación penal, con la consecuente vulneración en cadena de gran parte de las garantías del debido proceso.

La incorporación de limitaciones y regulaciones de carácter tecnológico en los programas de compliance ha llevado por ejemplo a que se presenten intensos debates sobre la esfera de privacidad de los trabajadores dentro de la empresa, a partir de la posibilidad de utilizar cámaras de video, o de mantener interferidas las comunicaciones en aparatos de propiedad de la empresa, así como una amplia capacidad de registro, tanto de pertenencias como de información personal y posteriormente utilizar esta información para legitimar despidos. Por otro lado, la posibilidad de establecer mecanismos de investigación interna compromete seriamente principios como la prohibición de autoincriminarse, de contar con asistencia técnica de un abogado, de guardar silencio y más aún, de ser investigado o juzgado por jueces o funcionarios competentes, en aplicación del principio de que solo al estado le es lícito ejercer el uso de medios coactivos para el establecimiento de sanciones.

Frente a estos desafíos, se habla de la existencia de dos modelos de compliance, uno que resulta más compatible con los principios del estado constitucional y que busca la prevención de actividades ilícitas, a través del fomento de una cultura de cumplimiento del Derecho y de construcción del "buen ciudadano corporativo"; y otro mucho más orientado al control a través de la intimidación y la sanción (panóptico empresarial), que es muy proclive a distorsionar la verdadera función del compliance, para convertirse en herramienta de disciplinamiento y persecución, con evidente vulneración de derechos, en los términos antes señalados ${ }^{62}$.

62 Sobre la distinción entre estos dos modelos, así como las 


\section{A MANERA DE CONCLUSIÓN. ¿UNA NUEVA DOGMÁtiCA PE- NAL PARA LAS PERSONAS JURÍDICAS?}

A lo largo del presente trabajo se han planteado los diferentes problemas que ofrece la posibilidad de justificar la atribución de responsabilidad penal para las personas jurídicas, pero aún aceptada ella, la falta de precisión existente sobre la escogencia del modelo de imputación que ha de regir esta forma de responsabilidad penal y más todavía, en caso de elegirse uno de ellos (el defecto de organización), la indeterminación de su ubicación en la teoría del delito, para finalmente mostrar las posibles tensiones y contradicciones que presenta uno de sus componentes fundamentales, el denominado compliance, tanto con las categorías de la teoría penal estándar como con principios fundamentales del mismo estado constitucional.

Este entorno ha llevado a que cierto sector de la doctrina postule la necesidad de elaborar una dogmática especial para la responsabilidad penal de las personas jurídicas, enfatizando en la noción de "culpabilidad constructivista"63 que parece ser el escollo más difícil de sortear al momento de hablar sobre responsabilidad penal de los entes ficticios; sin embargo, poco o nada se ha dicho sobre otros aspectos concretos que debería proponer tal nueva dogmática, así como tampoco sobre el rol que desempeñaría el compliance y sus funciones dentro de tal teoría.

implicaciones de las investigaciones internas (whistleblowing) en lo derechos de los trabajadores, MASCHMANN, Frank, "Compliance y derechos del trabajador", en Compliance y teoría del Derecho Penal, Marcial Pons, Buenos Aires, 2013, pp. 147 y ss

63 GÓMEZ-JARA DíEZ, “Autoorganización empresarial y auto rresponsabilidad empresarial", Revista Electrónica de Ciencia Penal y Criminología, 08-05-2006. 
Con este propósito y una vez más, partiendo de la teoría de los sistemas sociales autopoiéticos de LUHMANN, se dirá que la empresa, pero no cualquier empresa, sino exclusivamente aquella entendida como un sistema complejo de actividades económicas y humanas ampliamente diversificadas y con un esquema definido de roles para sus diferentes integrantes, siempre que establezca entre tales componentes un conjunto de relaciones de comunicación dinámica, capaz de generar valores propios o sea, autónomos de los valores individuales de sus integrantes y que por tanto definan una identidad propia a través de una cultura organizacional,seencuentradotadadelascaracterísticas especiales de autoadministración, autoconducción y autoorganización, pues se considera que tal cultura organizacional puede actuar de manera relativamente independiente a los designios de cada uno de sus miembros.

Si esto es verdad, se genera entonces un sistema de decisiones así mismo relativamente autónomo ${ }^{64}$ que a su vez exige de un sistema de vinculación a esas decisiones con las mismas características y ello solo es posible mediante la construcción de una suerte de "código del sistema" basado en determinadas premisas de decisión que se van produciendo y reproduciendo a lo largo del tiempo y con las vicisitudes de la práctica, obviamente condicionadas por las normas heteroimpuestas que regulan la actividad empresarial de que se trate. Estas premisas a su vez operan para la organización de manera análoga a como lo hacen los principios y las reglas de una Constitución para un estado, es

64 Se insiste en el término "relativamente" pues genuinamente se considera imposible llevar al extremo un criterio de independencia absoluta del sistema aún en contra de la voluntad de sus propietarios o administradores. 
decir, dan carta de nacimiento a la organización, la estructuran y establecen el conjunto de prerrogativas, funciones, facultades y límites de sus integrantes y por ello, deben estar dotadas de cierta estabilidad y rigidez que dificulte la posibilidad de que sean cuestionadas y reemplazadas con excesiva facilidad.

Solo si se acepta esta manera de funcionar, se puede avanzar a la consideración del sistema empresarial como un aparato cognitivo verdaderamente autónomo desde el punto de vista organizativo, capaz de expresar actos propios susceptibles de ser jurídicamente valorados mediante imputación penal; es decir, solo así se puede estructurar seriamente la noción del tan repetido modelo de culpa por defecto de organización, donde el compliance tenga una función integradora que provea el código del sistema o el análogo a la Constitución si se quiere, pues en él deberían contenerse las premisas de decisión (en lenguaje del código del sistema) o los principios y reglas (en términos de Constitución) a los que deben conformarse las actuaciones del sistema en sí mismo, así como de sus integrantes (propietarios, administradores, trabajadores, etc.), cuya fuerza vinculante radique en obligación prima facie que tienen todos sus integrantes, de someterse al Derecho -en este caso bajo la forma de coregulación a que se hizo referencia en otra parte de este mismo trabajo- y la correlativa sanción (administrativa, civil o penal) a que se exponen en caso de quebrantamiento de sus previsiones, en el ámbito penal, mediante la constatación de que tal hecho ha dado lugar a una actuación defectuosa en el ámbito de organización, donde además se aprecia con claridad que la función esencial de la pena es la vigencia, tanto de esa norma vulnerada como de la norma social protegida (bien jurídico tutelado), independientemente de las otras funciones conocidas de comunicación de desaprobación social y de pretensión disuasiva. 
La construcción de una dogmática penal especial sobre estas bases supondría igualmente un cambio de paradigma epistémico, pues tornaría innecesario analizar, como actualmente se lo hace con las categorías estándar, la ubicación y características de esta forma de responsabilidad penal en la así denominada Teoría del Delito y por otra parte, obligaría a construir nuevas categorías superadoras de los métodos de análisis tradicionales sobre aspectos como la causalidad, autoría e imputación objetiva y en esta última, especialmente sobre los conocimientos especiales y la prohibición de regreso, principalmente cuando deba analizarse la responsabilidad penal de los compliance officers. 


\section{BIBLIOGRAFÍA}

ÁVILA Santamaría, Ramiro, "La (in) justicia penal en la democracia constitucional de derechos: una mirada desde el garantismo penal", Universidad Andina Simón Bolívar, Quito, 2013.

BaCigalupo, Enrique, "Complience y Derecho Penal. Prevención de la responsabilidad de directivos y de empresas", Hammurabi, 2012.

BACIGALUPO, Silvina, "La responsabilidad penal de las personas jurídicas”, Bosch, Barcelona, 1998.

BERMEJO, Mateo G./ Palermo, Omar, "La intervención delictiva del compliance officer", en "Compliance y Teoría del Derecho Penal”. AAVV, Marcial Pons, Madrid, 2013.

BOCK, Dennis, "Compliance y deberes de vigilancia de la empresa", en "Compliance y Teoría del Derecho Penal". AAVV, Marcial Pons, Madrid, 2013.

CASAS Ismael y Álvarez Manuel, “ ¿Sirve de algo un programa de complience penal?..." disponible en http://www. uria.com/documentos/publicaciones/2903/documento/ articuloUM.pdf?id=2974.

FEINBERG, Joel, “Abortion”, disponible en http://www.ditext. com/feinberg/abortion.html.

FERRAJOLI, Luigi. "La esfera de lo indecidible y la división de poderes", Estudios Constitucionales, Año 6, No. 1, Centro de Estudios Constitucionales, Universidad de Talca, Chile, 2008, pp. 337-343, disponible en http://www.cecoch.cl/ docs/pdf/revista_ano6_1/Laesfera17.pdf, 
FERRAJOLI, Luigi. "Los Fundamentos de los derechos fundamentales". Trotta, Madrid, 2005.

FERRI-RICCHI, Amedeo, "El Contrato de Swap como tipo de derivado", tesis doctoral, Universidad Complutense de Madrid, Facultad de Derecho, Departamento de Derecho Mercantil, Madrid, 2013, disponible en http://eprints. ucm.es/22814/1/T34726.pdf.

GARGARELLA, Roberto. "De la injusticia penal a la justicia social" Siglo del Hombre, Universidad de los Andes, Bogotá, 2008.

GOMEZ-JARA DÍEZ, Carlos, "Autoorganización empresarial y autorresponsabilidad empresarial", Revista Electrónica de Ciencia Penal y Criminología, 2006, No. 8-05, disponible en http://criminet,ugr.es/recpc

JAKOBS, Gunther, "La Imputación Objetiva en Derecho Penal", Trad. Manuel Cancio Meliá, 4ta. reimpresión, Ad Hoc, Buenos Aires, junio de 2009.

JESCHECK, Hans-Heinrich, "Tratado de Derecho Penal, Parte General", Trad. Miguel Olmedo Cardenete, Quinta edición, Comares, Granada 2002.

KANT, Emanuelle, Metaphysik der Sitten 1797, Cfr: SÁNCHEZ DE LA TORRE en Domingo (dir), Juristas Universales, II, Madrid-Barcelona, 2004.

KAUfMANN, Armin, "Dogmática de los delitos de omisión", trad de la $2^{\circ}$ edición de Cuello Contreras/Serrano González de Murillo, 2006, pp. 297.

KUHLEN, Lothar, "Cuestiones fundamentales de compliance y Derecho Penal", en "Compliance y teoría del Derecho Penal, VVAA, Marcial Pons, Buenos Aires, 2013, pp. 67-68 
LUHMANN, Niklas, "Sistemas Sociales: Lineamientos para una teoría general”, Anthropos, Barcelona, 1998.

MASCHMANN, Frank, "Compliance y derechos del trabajador", en "Compliance y teoría del Derecho Penal", Marcial Pons, Buenos Aires, 2013.

NiETO MARTíN, Adán, "Problemas fundamentales del cumplimiento normativo en el Derecho Penal", en "Compliance y teoría del Derecho Penal", VVAA, Marcial Pons, Buenos Aires, 2013.

PASTOR R, Daniel, "La discusión actual en torno de la culpabilidad", en "Problemas actuales de la Parte General del Derecho Penal, VV.AA”, Ad Hoc, Buenos Aires, noviembre de 2010 .

REAL ACADEMIA ESPAÑOLA, "Diccionario de la Lengua Española", 22 $2^{\circ}$ publicación, 2001, disponible en http:// www.rae.es/recursos/diccionarios/drae.

ROXIN, Claus "Autoría y dominio del hecho en Derecho Penal", $6^{\circ}$ ed., 1998, p. 515, aunque reconoce alguna excepciones a esta regla.

,"La imputación objetiva en el Derecho penal”, IDEMSA, 1997.

SILVA SÁNCHEZ, Jesús María, "Deberes de vigilancia y compliance empresarial", en "Compliance y Teoría del Derecho Penal". AAVV, Marcial Pons, Madrid, 2013

SuTHERLAND Edwin, "Principios de Criminología", Chicago University Press, Chicago, 1924

VARELA, Francisco J.; \& MATURANA, Humberto R., "De máquinas y seres vivos: Una teoría sobre la organización biológica”, Ed. Universitaria, Santiago de Chile, 1973. 


\section{LINKOGRAFÍA}

http://www.academia.edu/3480864/El_caso_Enron_Fracaso_ de_una_de_las_empresas_mas_poderosas_de_estados_unidos

http://fraudescontables.blogspot.com http://escritosderechopenalcamiloencisov.blog spot. com/2013/05/grandes-fraudes-financieros-lecciones.html.

http://interamerican-usa.com/articulos/Gob-Corp-Adm/ArtParmalat.htm

http://queaprendemoshoy.com/el-caso-jp-morgan-que-fue-loque-sucedio-realmenteii/?preview=true\#.T7wjX0Vp5nA http://www.academia.edu/3667747/Caso_Siemens

ht tp://www.elmundo.es/elmundo/2013/09/17/ economia/1379407595.html

http://www.expansion.com/2014/08/07/empresas/ banca/1407392156.html

http://perspectivasinternacionales.javerianacali.edu.co/pdf/6.107.pdf, 